\title{
O SERTÃO SUL-MARANHENSE: UM ESPAÇO GEOGRÁFICO EM DES-RE-CONSTRUÇÃO
}

\author{
Rosimary Gomes Rocha \\ Universidade Federal do Maranhão, Curso de Licenciatura em Ciências Humanas/Geografia, Grajaú, MA, Brasil \\ rosimary.rocha@ufma.br
}

\author{
Marcos Nicolau Santos da Silva \\ Universidade Federal do Maranhão, Curso de Licenciatura em Ciências Humanas/Geografia, Grajaú, MA, Brasil \\ marcos.nicolau@yahoo.com.br
}

\begin{abstract}
RESUMO
O espaço sul-maranhense está caracterizado por uma identidade regional construída mediante o entrelaçamento de formas e funções tradicionais e modernas, em que coexistem práticas do modo de vida sertanejo e dinâmicas espaciais modernizadoras do território. Para tanto, entende-se que as práticas culturais possuem papel relevante para o entendimento da organização e construção do lugar. Para este estudo, enquanto recurso metodológico, utilizamos de revisão bibliográfica que aborda o processo de construção histórico-regional por criadores de gado, bem como foram utilizados conceitos para pensar o lugar e os sujeitos. Completou-se a metodologia com o trabalho de campo, para observação e análise socioespacial, além de conversas com os sujeitos sertanejos guiadas e analisadas por meio da rememoração. Dessa forma, o contra-argumento encontrado é que, mesmo quando o Sertão apresenta-se como uma categoria inexistente, segundo alguns estudiosos, em decorrência dos eventos modernizadores que foram inseridos na região ao longo dos últimos cinquenta anos, perscruta-se que aí ainda há elementos que condizem com formas de vida ligadas ao tradicional, havendo um entrelaçamento de lógicas sociais anteriores com as constantes na atualidade.
\end{abstract}

Palavras-chave: Sertão Sul-maranhense. Sujeitos. Identidade. Lugar.

\section{THE SOUTH SERTÃO OF MARANHÃO: A GEOGRAPHICAL SPACE IN DES- RE-CONSTRUCTION}

\begin{abstract}
The space of South Maranhão is characterized by a regional identity built through the interweaving of traditional forms and functions with modern ones, in which there are practices of the Sertanejo way of life and modernizing spatial dynamics of the territory. To this end, we understand that cultural practices have a relevant role in the understanding of the organization and construction of the place. For this study, as a methodological resource, we use bibliographic review that addresses the process of regional historical construction by cattle breeders, as well as the concepts we use to think about the place and the subjects. The methodology was completed with fieldwork, for observation and socio-spatial analysis in addition to conversations with the sertanejos subjects who are guided and analyzed through the remembrance. Thus, the counterargument found is that even when the Sertão presents itself as a non-existent category, according to some scholars, as a result of the modernizing events that have been inserted in the region over the last fifty years, we have observed that there are still elements that match with forms of life linked to the traditional, and there is a joining of previous logics with those constant today.
\end{abstract}

Keywords: South Sertão of Maranhão. Subjects. Identity. Place.

\section{INTRODUÇÃO}

A região sul-maranhense está inserida, contemporaneamente, no contexto da mundialização econômica por meio do agronegócio no qual a sojicultura apresenta-se como carro-chefe da produção. Soma-se a isso todo um contexto de instalação no território de aparatos tecnológicos, financeiros e empresariais com formas e funções voltadas a favorecer a existência de fixos e fluxos que dinamizam as relações econômicas aí inseridas. Importante ressaltar que, historicamente, a 
apropriação espacial da região se deu por diferentes sujeitos, com características identitárias próprias e divergentes, nos quais, destacam-se os autóctones (indígenas), os vaqueiros que aí chegaram ainda no século XVIII e os sulistas, dedicados ao agronegócio. Esses sujeitos mantêm suas existências por meio de estratégias, ações e intencionalidades, nas quais fazem parte as práticas de reprodução socioespacial, havendo uma combinação de valores e de lógicas sociais anteriores com as atuais.

Ressalta-se que, nesse estudo, os elementos geo-históricos nos conduzem a pensar a formação territorial sul-maranhense, por meio dos elementos e acontecimentos transformadores do espaço e do sujeito sertanejo, dentre os quais os componentes fitogeográficos possuem influência no modo de vida e nas identidades mobilizadas na formação do Sertão enquanto lugar de vida. Para tanto, identidade e lugar são conceitos privilegiados para a produção do sentido existencial dos sertanejos. Nesse sentido, o que se propõe é mais do que demonstrar a materialidade, mas dar visibilidade ao invisível. Para tal, recorremos à Almeida (2013, p. 45), para quem "as geografias da invisibilidade que aí estão sem estar - marcam nossos espaços existenciais tanto quanto as geografias visíveis e cartografáveis".

Desse modo, para a construção desse artigo, o estruturamos de forma a levantar os principais elementos que enfatizam a historicidade do Sertão sul-maranhense, seguida de uma abordagem sobre lugar e identidade, para que, assim, possamos pensar o sujeito sertanejo, por meio de suas práticas, ações e intencionalidades.

\section{COMPONENTES HISTÓRICOS FORMADORES DO SERTÃO SUL-MARANHENSE}

Autores como Carvalho (2000), Paula Ribeiro (2002) e Cabral (1992) elencaram em suas obras a grande importância e, até mesmo, como fator definidor da ocupação do sertão sul-maranhense pelos criadores de gado, os elementos da natureza, os quais possuem significação na construção da identidade sertaneja. Tais autores nos ajudam a pensar esse espaço enquanto possuidor de singularidades interligadas em/por relações identitárias, que dentre outros aspectos incluem os componentes culturais, políticos, históricos e geográficos de uma região (ASKENAZI, 2010; ALMEIDA, 2009; LAP, 2004; CASTELLS, 1999).

Para relacionar esses fatores à história de ocupação da localidade, precisamos dar ênfase aos acontecimentos históricos, sobre os quais, Andrade (1998, p. 205) destaca:

[...] correntes de vaqueiros, de criadores de gado oriundos da Bahia subiram os rios da vertente oriental [...], atravessaram os interflúvios existentes entre as nascentes destes rios - Chapada Diamantina - e as nascentes dos afluentes da margem direita do São Francisco e, após conquistar o vale do grande rio, subindo os cursos dos seus afluentes da margem esquerda, atravessaram as chapadas que separam o Piauí da Bahia e se espraiaram pelas terras drenadas para o rio Parnaíba. Dominaram assim, o espaço piauiense [...] e a porção meridional do Maranhão.

Nesse sentido, a região que tem o Cerrado como vegetação predominante e a presença de rios caudalosos e perenes apresentou esses elementos como influenciadores para a instalação das fazendas de gado. O que condicionou Paula Ribeiro (2002, p. 68) em seu estudo sobre o Sertão maranhense escrever que: "Pastos Bons ${ }^{1}$ foi então uma expressão geográfica, uma denominação regional geral, dada pelos ocupantes à imensa extensão de campos abertos para o ocidente em uma sucessão pasmosa em que ao bom sucedia o melhor". Assim, os componentes da natureza, influenciaram o estabelecimento de currais de gado no Sul do Maranhão, sendo que as comunidades indígenas, já existentes na localidade, se configuraram como único entrave, tendo seu contingente populacional bastante reduzido em batalhas conflituais com os recém-chegados.

Ao longo do tempo a existência sertaneja foi construída por meio de conflitos, não somente com os indígenas, como também, entre famílias rivais e com maneiras de se rebelarem contra a Coroa. Esse sujeito foi construindo modo de vida próprio, muito próximo à natureza, com saberes que lhe permitiu fabricar e produzir os bens necessários à manutenção da vida, habitando em situação de semiisolamento em decorrência da inexistência de estradas, havendo apenas trilhas aonde os mesmos

${ }^{1}$ Antigo território que compreendeu a parte Centro-Sul do Maranhão e que recebeu essa denominação no século XVIII devido à grande quantidade de pastagens férteis e naturais. 
percorriam a pé ou em lombo de animais, principalmente muares e cavalos.

Situação que foi sendo modificada após 1950, com o surgimento das primeiras estradas e dos primeiros automóveis na região e que foi impactada nos anos de $1980 \mathrm{com}$ a introdução de tecnologias modernas para a produção agropecuária em moldes do agronegócio. Com isso, houve transformações de forma acentuada no espaço, influenciadas pela mudança também dos sujeitos. Nesse sentido, entender o sertanejo, hoje, vai bem mais além do que enxergá-lo como um habitante do espaço rural, pois há uma diversidade de elementos que fazem parte da vida desses sujeitos. Então, o modelo de vida arcaico, possuidor de instinto natural, no qual thes eram desconhecidas as letras, as artes e até mesmo as mecânicas, no qual viviam como os selvagens, conforme descrito por Paula Ribeiro (2002, p. 117), é inexistente hoje.

Logo, as relações socioespacias e o tempo dessas relações, atualmente, são outras. O outro não é só o indígena, como também, o grande produtor com suas técnicas avançadas, a grande fluidez espaço-temporal e a necessidade de se inserir nesse processo, mudando as dimensões da vida. Assim, a identidade vai se alterando e o lugar passa a possuir novas conotações políticas, econômicas e sociais.

\section{LUGAR E IDENTIDADE NO PROCESSO DE CARACTERIZAÇÃO DO SERTÃO SUL- MARANHENSE}

A significação que um grupo social constrói acerca do seu espaço de vivência, de suas técnicas de trabalho, no seu modo de se relacionar com a natureza e de sua sociabilidade é repleta de simbologias que se dão por meio de vínculos de pertencimento. Fazer parte de um lugar encontra sentido na perspectiva de que existe o Outro, o qual não é pertencente a esse lugar, e que está além da fronteira, pois as ações, modos de vida, as temporalidades sociais não são iguais. Assim, a identidade se caracteriza por/pela diferença (ALMEIDA, 2009; CRUZ, 2007; GENIS, 2004; HALL, 1997). O que faz com que, nesta perspectiva, só exista identificação em relação ao ser diferente, o que consequentemente origina a existência de conflitos e fronteiras psicológicas e sociais.

Corroborando com a mesma ideia, Penna (1992, p. 60) infere que, "deste modo as identidades sociais, por sua vez, demarcando as fronteiras do grupo (seus limites) e estabelecendo tanto a coesão do "nós" quanto a diferenciação em relação aos "outros" indicam com quem e como interagir". Havendo destaque, nesse processo, os conflitos, já que a existência da diferença inclui embates por interesses divergentes. Nesse movimento, a questão da aceitação, seja total ou parcial, encontra-se estabelecida, na maioria das vezes, mediante um jogo de forças estabelecidas direta ou indiretamente.

Quando perscrutamos o sertão sul-maranhense e os sertanejos como lugar e sujeitos de nossa análise, objetivamos entender as transformações socioespaciais por meio das trajetórias, experiências de vida e significações e, dessa forma, podermos abstrair suas identidades constituídas historicamente. Assim, partimos do pressuposto colocado por Castells (1999, p. 22), em que "entende-se por identidade a fonte de significado e experiência de um povo". E sobre ser construída de forma histórica, Lap (2004, p. 95) assinala que, "a identidade flui continuamente como um rio, unindo passado, presente e futuro. Ela carrega as mensagens da comunidade, mensagens que se manifestam igualmente em cada indivíduo". A identidade desses sujeitos foi/é construída em referência ao Outro, seja o indígena, que já se encontrava na localidade quando da chegada dos sertanejos vaqueiros, seja em relação aos de fora, o citadino, o mineiro, o sulista, o paulista.

Levando em consideração que o espaço é continuamente modificado, principalmente pelas forças da ação do capital, que age em busca de modelá-lo conforme suas demandas econômicas e políticas, entendemos por esse viés que, conjuntamente, os sujeitos também são modificados. Ou seja, o espaço muda e, com ele, o sujeito.

No concernente à cultura sertaneja no Sul do Maranhão ter, historicamente, uma íntima relação com os fatores da natureza, não queremos aqui partir de um determinismo natural ou de um rigor dos aspectos físicos da natureza. Esse componente se relaciona ao modo como o homem lida com o espaço nos diferentes momentos históricos, nos quais, as ações são demandadas pelas técnicas, que quanto mais densas, mais usado é o território, em que aí vai se estabelecendo um vínculo de identificação com o espaço e, portanto, passa a existir um lugar objetivo e subjetivo. 
De acordo com Cruz (2007, p. 26):

\begin{abstract}
O espaço de referência identitária refere-se ao recorte espaço-temporal (os meios e os ritmos) em que realiza a experiência social e cultural, é nele que são forjadas as práticas materiais (formas uso, organização e produção do espaço) e as representações espaciais (formas de significação, simbolização e imaginação do espaço) que constroem o sentimento e o significado de pertencimento dos grupos ou indivíduos em relação a um território. O espaço geográfico pode ser referência para a construção da identidade em sua dimensão físico-natural, social e simbólica.
\end{abstract}

Assim, a identidade sertaneja sul-maranhense caracteriza-se por ser condicionada por práticas socioespaciais, estabelecendo modos de vida e de vínculo com o lugar. Como indica Relph (2012, p. 27), "é por meio de lugares que indivíduos e sociedades se relacionam com o mundo, e que essa relação tem potencial para ser ao mesmo tempo profundamente responsável e transformadora".

O forte vínculo faz-se pelo contexto histórico, no qual os sujeitos sertanejos foram criando, com base em trajetórias familiares, relações de pertencimento, de poder e de referência identitária com esse lugar. As dimensões significativas do lugar, que na realidade é o sentido que se atribui a este ou àquele (o meu, o seu ou o nosso lugar), são pensadas em termos geográficos a partir da experiência, do habitar, do falar e dos ritmos das transformações (OLIVEIRA, 2012, p. 16). E é somente a partir do seu "situamento" que os sujeitos conseguem enxergar a si mesmo e ao mundo, e, dessa forma, desferir suas ações num espaço concreto e em um tempo específico. Como bem expressa Chaveiro (2012, p. 251), "é pela ação que se pratica o lugar pela vivência, desenvolvendo símbolos, manuseando coisas, desferindo representações que alimentam o devir".

A imagem acerca do lugar, conduzida pelos aspectos climáticos, vegetais, hidrográficos, formas do relevo, ou seja, pelos elementos físicos e biofísicos, levam à construção da paisagem que o sujeito carrega em sua experiência de vivência, e que costura modos de vida juntamente com as relações de sociabilidade. Portanto, é o lugar experienciado como aconchego, centro de significados, que levamos dentro de nós (OLIVEIRA, 2012; TUAN, 1995). Ou o lugar consciente do tempo social histórico, recorrente e mutável, no transcorrer das horas do tempo em um espaço sentido dentro de um lugar interior ou exterior (OLIVEIRA, 2012, p. 16).

Tal discussão nos remete ao entendimento da existência do sertanejo, enquanto sujeito, que habita e reelabora suas práticas, em um tempo de apropriação material e imaterial do espaço geográfico. Não obstante, as marcas espaciais ocorrem de forma múltipla e distinta, e, por isso, pensar as singularidades e particularidades de um lugar e dos sujeitos que aí habitam faz-se necessário. Estes pressupostos vão ao encontro com o Ser e o Viver no Sertão.

Nessa perspectiva, Mello (2014, p. 65) destaca que "o lugar transcende a materialidade, mas não está dissociado desta, pois aos objetos os homens atribuem significados que são construídos na vivência individual ou dos grupos". Entendemos que a efetivação da materialidade é intermediada pela imaterialidade, ou seja, pela subjetividade, que está atrelada às ações, comportamentos, modos de ver e sentir o mundo pelos sujeitos.

Tais elementos estão inclusos no cotidiano do sertanejo, que normalmente desenvolvem relações sociais, políticas, econômicas e identitárias ligadas diretamente ao seu lugar de vida - o Sertão -, e à cidade mais próxima, sem, no entanto, ter sua vida dissociada das relações com os processos econômicos globalizantes.

\title{
O OLHAR PARA SI: O QUE CARACTERIZA O SER SERTANEJO
}

A construção territorial do Sul do Maranhão, enquanto espaço sertanejo, deu-se ancorada em formas arcaicas de criação do gado à solta nas chapadas, no fazer dos roçados onde era produzida a maior parte dos alimentos, na maneira de se relacionar com a natureza e nos longos trajetos percorridos para que fosse possível fazer a negociação de compra e venda do gado, a obtenção do sal e de alguns outros poucos mantimentos existentes para a comercialização.

Nesse pressuposto, a denominação sertão se configurou como espaço pertencente ao interior do Brasil, com traços relacionados aos costumes, ao econômico e à organização sociocultural diferentes daqueles do litoral. A respeito disso, Vicentini (2016, p. 30) nos explica que, "no pensamento social brasileiro, a Literatura de certa maneira auxiliou a transformar o conceito de sertão em um conceito 
cumulativo, embora dicotômico (sempre oposto ao litoral ou à capital)". E acrescenta que nele se encontram:

\begin{abstract}
O sentido espacial - o sertão é o interior longínquo e despovoado, ou povoado por uma raça mestiça, quando não é o locus amoenus do campo idealizado; o sentido econômico - o sertão mantém uma economia distante da economia da metrópole e do litoral, agrária e subdesenvolvida frente à economia industrial e mais desenvolvida da metrópole; o sentido social - o sertão mantém outro tipo de associação de membros, uma associação mais comunitária, outros tipos de usos e costumes; a aliança sociopolítica, o poder dos coronéis e o desvalimento dos camaradas; o sentido psicossocial, na perspectiva da antropologia - o sertão detém um universo psíquico mais ritualizado, com formas de pensamento mais míticas e agônicas; o sentido histórico - onde o sertão detém a chave de nossa história típica, a partir das entradas e bandeiras; o sentido do imaginário propriamente falando - quando o sertão avulta como local de vida heroica ou trágica, de vida identitária; e outros tantos, que salientam uma perspectiva romântica ou realista, ou conservadora, ou de denúncia social, ou determinista etc. (VICENTNI, 2016, p. 30).
\end{abstract}

No Maranhão, esses componentes estavam bem presentes até meados do século $X X$, sendo que, a partir desse momento, tais elementos vão sofrendo rupturas, que culminam, principalmente, na chegada dos eventos modernizadores, que passam a atuar no território maranhense de forma acentuada após 1970. São as introduções de estradas pavimentadas, ferrovias, portos, aeroportos, cercamento das propriedades, migrações rurais, instalações de Projetos de Assentamentos, criação de reservas indígenas e ambientais, crescimento urbano, instalação do agronegócio personificado nas pessoas vindas do Sul do Brasil, na região de Balsas, espraiando-se para demais municípios no seu entorno e para o Baixo Parnaíba. Houve, dessa forma, um "chamamento" para que o sertanejo mudasse também a sua vida e tentasse, dessa forma, adequar-se ao novo modelo que passa a reger o espaço sul-maranhense desde então, culminando num processo de transição territorial, resultado da incorporação e da dominação do capital monopolista e oligopolista.

Dessa feita, a chegada do estranho vai interferir na lógica local, o que nos condiciona a pensar que houve um "desaparecimento" do sertão maranhense decorrente de processos de reocupação ao longo da segunda metade do século XX. Que, no caso, trata-se de uma questão nominal e simbólica, embora afete a forma na qual o trabalhador rural, que vive no campo ou em pequenas cidades, mas que tem a vida ligada ao trabalho na terra, reconheça a si mesmo e o seu lugar de vivência.

Todavia, de acordo com os relatos dos entrevistados e a forma de vida encontrada a partir de trabalho de campo, pudemos perceber que o processo de transição nominal, simbólica e cultural não foi completo, de tal maneira que os sujeitos inclusos na pesquisa se reconhecem sertanejos, estando suas existências atreladas ao modelo rural e vinculados a saberes apreendidos na infância com os pais, tios e avós.

Para um entendimento mais detalhado, organizamos os relatos dos entrevistados em um quadro acerca do que constitui ser sertanejo, em que podemos perceber significações diferentes, apesar de vermos, em todas as falas, que a vida está ligada àquele lugar por determinações do ser dali. Importante enfatizar que, os entrevistados 01,02 e 03 são homens em idades entre 70 e 80 anos, já o entrevistado 04 está numa faixa etária dos 40 aos 50 anos.

Tais relatos demonstram que o Ser sertanejo está muito mais atrelado a um sentimento de pertencer ao lugar, em decorrência das experiências vividas desde a infância, do que ao habitar em si esse espaço. Nesse propósito, os pais tiveram grande importância para a formação dos saberes adquiridos e acerca do modo de vida apreendido, porém alterado com o passar do tempo. Nesses conformes, o sertanejo também tem criado outros espaços, outros territórios, à medida que recriam a si próprios. Logo, os valores humanos repassados de pai para filho na década 1950 estão muito distantes dos que são repassados hoje, pois esses sujeitos têm construído outras significações. O que faz com que os componentes supracitados nos levem a pensar de acordo com o colocado por Brandão (2009), segundo o qual, vários antropólogos, entre eles Clifford Geertz, têm utilizado pensar as culturas por meio das redes, das teias, das tramas, dos contextos, dos mapas e dos sistemas.

Teias, tramas, redes e mapas dos mais diversos cenários e contextos culturais, com que atribuímos um ou vários sentidos aos espaços de vida que geramos. $E$ também aos mundos sociais que criamos, destruímos e recriamos, socializando porções de uma natureza intencionada, transformada em fragmentos e sistemas de cultura. A 
mesma cultura que nos toma como indivíduos biológicos (seres da natureza) e nos transforma em pessoas sociais (sujeitos de uma cultura). Uma ideia que nos vem de Marx lembra que somos seres naturais, mas seres naturalmente humanos. Nós, construtores de espaços e de lugares, de terras, de territórios, de casas e nomes de casas. E também de conceitos, canções e teorias a respeito dos tempos e dos espaços que de algum modo pertencem a nós, na mesma medida em que pertencemos a eles (BRANDÃO, 2009, p. 17).

Quadro 01 - Relatos dos depoentes acerca do que significa ser sertanejo

\begin{tabular}{|l|l|l|}
\hline Entrevistados & \multicolumn{1}{|c|}{ Relatos } & \multicolumn{1}{|c|}{ Significação } \\
\hline Entrevistado 01 & $\begin{array}{l}\text { "Sou um sertanejo da roça, mas } \\
\text { atualizado na cidade. A roça é a } \\
\text { terceira coisa da minha vida. Só depois } \\
\text { de Deus e de meus filhos". }\end{array}$ & $\begin{array}{l}\text { Há nessa fala uma reivindicação de } \\
\text { modernidade não conflitante com } \\
\text { tradicionalismo: é sertanejo (do mato), } \\
\text { todavia, atualizado. }\end{array}$ \\
\hline Entrevistado 02 & $\begin{array}{l}\text { "Eu sou sertanejo mesmo, legítimo. O } \\
\text { sertão é lugar de trabalho". }\end{array}$ & $\begin{array}{l}\text { Sertão como terra de conquista, de lida } \\
\text { de labuta, de gente que arregaça as } \\
\text { mangas. }\end{array}$ \\
\hline Entrevistado 03 0 "Nóis somo sertanejo de coração. \\
& $\begin{array}{l}\text { Somo daqueles que só quer ir na ponto de vista, sertanejo tem } \\
\text { cidade só pra fazer alguma compra ou } \\
\text { se for pra visitar algum parente". }\end{array}$ & $\begin{array}{l}\text { o sentido genérico de pessoa do mato, } \\
\text { matuto, caipira. É um elemento de } \\
\text { campesinidade. }\end{array}$ \\
\hline Entrevistado 04 & $\begin{array}{l}\text { "Eu me orgulho de ser sertanejo. Sou } \\
\text { sertanejo porque ainda vivo no sertão e en } \\
\text { meu pai me ensinou a trabalhar no } \\
\text { sertão, um meio de ganhar o sustento } \\
\text { lá no sertão, por isso eu não saí de lá". }\end{array}$ & $\begin{array}{l}\text { Sertão enquanto lugar de trabalho, em } \\
\text { para filho. Aqui há um know-how. }\end{array}$ \\
\hline
\end{tabular}

Fonte: ROCHA, R. G. Trabalho de campo, 2017.

Há um sentimento de fazer parte de um espaço, que, de maneira intencional, é transformado em lugar através de nomes, símbolos e significados. Exemplo disso se encontra nos nomes dados às fazendas, como Monte Alegre, Alegria, Canto da Lagoa, São João, Piranhas, Sobradinho, que os coloca como lugares sagrados, tradicionalmente passados de pais para filhos, colaborando para uma continuação da geração no espaço material ou, como indica Brandão (2009, p. 20), ao usar do verbo "espaciar", "sugere-se que o homem gera ou libera lugares quando cria os seus espaços". E acrescenta:

Espaciar, gerar em um espaço dado um espaço criado, fruto da imaginação e da ação humana, não é apenas construir materialmente um lugar situado, mas é, antes, liberar lugares: fazê-los acontecer. Existirem para nós e não apenas em si mesmos. Virem a ser seres - e não apenas contextos - da cultura e, nela, da linguagem (BRANDÃO, 2009, p. 20).

Sobre o termo espaciar, não podemos partir de uma redefinição do sujeito e do espaço como um todo. Se o arcaico e a tradição sofreram transformações ao longo destes quase setenta anos, isso não significa uma fragmentação absoluta, por isso faz-se importante pensar, pelo viés da transição, a forma como o território Sertão sul-maranhense foi sendo diluído e como os sujeitos estão nesse processo, ao mesmo tempo em que se reinventam.

Destarte, durante o trabalho de campo, constatamos a existência de artefatos utilizados para a execução de trabalhos domésticos, com o labor com o gado e na maneira de produzir os alimentos. Esses aspectos indicam a permanência de determinados saberes no cotidiano desses sujeitos, o que remete a um modelo de vida tradicional, conforme pode ser visto nas figuras 1 e 2, em que as lógicas preexistentes não são extintas, ou seja, os saberes não são anulados. Em praticamente todas as residências que visitamos observamos que há energia elétrica e utensílios como geladeiras, televisores, ventiladores. Todavia, há a manutenção de formas de armazenamento de água, máquina de costura, entre outras, que não necessita da utilização da energia elétrica. 
Figura 1 - Pote, filtro de barro, copos de alumínio e bilhar

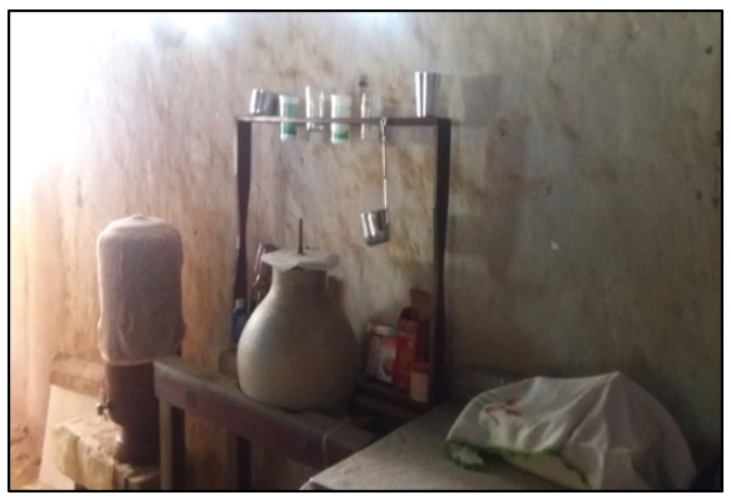

Fonte: ROCHA, R. G. Trabalho de campo, 2017.
Figura 2 - Máquina de costura manual, ano de

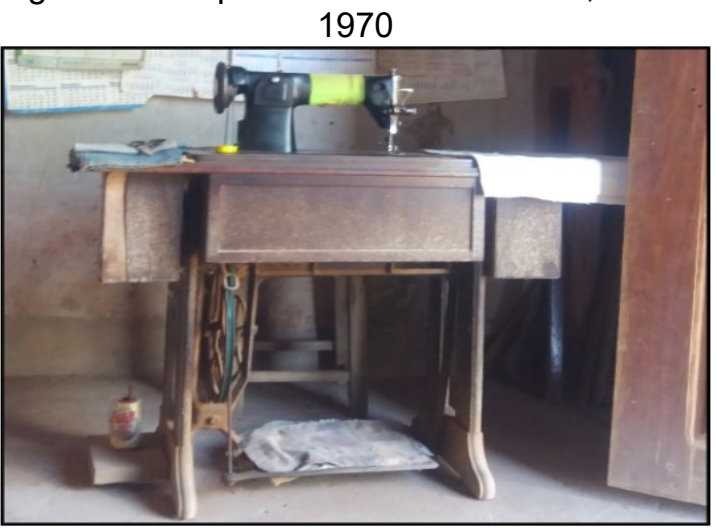

Fonte: ROCHA, R. G. Trabalho de campo, 2017.

Como já se sabe, a distância da cidade em relação ao Sertão não é mais a mesma de outros tempos, graças à melhoria das estradas, construção de pontes e presença de automóveis. Mesmo assim, existem hábitos que são mantidos, porque fazem parte dos saberes adquiridos e que passaram a constituir-se em sabores apreciados no Sertão, a saber, a carne de sol, sempre bem seca, as hortaliças plantadas no canteiro cercado, para que porcos e galinhas não mexam (Figuras 3 e 4).

$\mathrm{E}$ a respeito do dormir em rede, muitos sujeitos mantêm esse hábito pelo fato de terem se acostumado. Consoante eles mesmos se expressam, não gostam de dormir em cama, pois se acostumaram, desde crianças, a dormir em redes.

Figura 3 - Carnes de gado secando ao sol

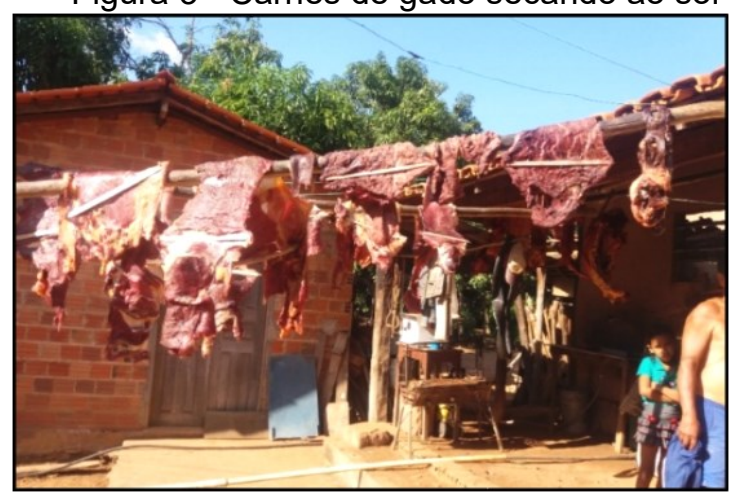

Fonte: ROCHA, R. G. Trabalho de campo, 2017.
Figura 4 - Cultivo de hortaliças

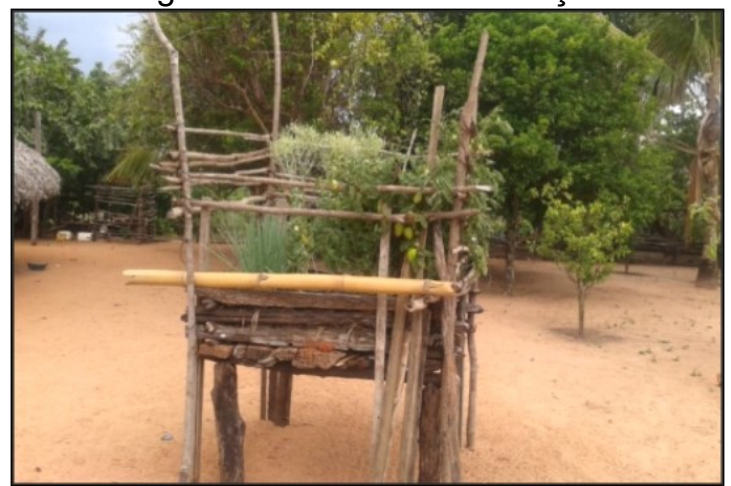

Fonte: ROCHA, R. G. Trabalho de campo, 2017.

$\mathrm{Na}$ verdade, o que existe é uma combinação dos atributos anteriores com os atuais no espaço pertencente aos sertanejos. Em locais onde foram erigidas fazendas ancoradas no modelo agroindustrial, as lógicas sociais, assim como a estrutura, a forma e a organização são outras. São, em relação ao primeiro, lugares situados, compostos de conquistas, apropriações e transformados pelos sujeitos que aí habitam, "movidos pelas palavras e imagens, símbolos e sentidos, ideias e imaginários" (BRANDÃO, 2009, p. 21).

Um espaço político, pois ali uma polis se instaura. Um espaço econômico, pois ali se reproduzem os bens da terra (as coisas da natureza tornadas objetos da cultura), ali eles circulam e ali, no mercado para onde de um modo ou de outro, todos convergem, e onde são trocados bens, serviços e sentidos. [...].

Um cenário, um ambiente, uma paisagem, um território, um bairro rural, uma vila, uma cidade, uma metrópole em que, em primeiro lugar, está situado um onde-euhabito, um onde-nós-vivemos. Lugares onde trabalhamos e produzimos bens e serviços, como querem os economistas. E, no entanto, um multiforme cenário de símbolos, mais do que de pedras ou de barro. Símbolos e aquilo através do que transformamos um solo de terra em um chão de sentidos, e algumas pedras em um 
alicerce humano de identidade. Criar o lugar onde se habita. Isto é, transformar instrumentalmente ambientes da natureza em habitats humanos, dotando-os da substância de nossos atos transformados em gestos tornados nomes, palavras, desenhos, preceitos de vida, gramáticas do conviver, sistemas de imagens, de ideias, ideologias, ideários, imaginários (BRANDÃO, 2009, p. 21).

Importante entender, então, qual a posição que ocupa o sertanejo diante dos novos atributos presentes, que exigem um remodelar de vida, quais as representações inclusas em suas práticas e quais os significados produzidos em suas vidas. Desse modo, as práticas que os representavam anteriormente, por exemplo, os saberes em relação ao cultivo das roças, ao tempo lunar, à religiosidade, à solidariedade, entre outros, podem não ocupar mais um lugar tão relevante. Nesse sentido, com a intenção de analisarmos a maneira como se veem inseridos na atual conjuntura da dinâmica socioespacial na região, interessamo-nos saber o que mudou para os entrevistados no percurso de suas existências.

Hoje está tudo estruturado, tem energia elétrica, água encanada, estrada boa, agora tem telefone, televisão, tem tudo. Hoje eu tenho transporte, tenho carro, tenho moto.

Está bem melhor, pra nóis mesmos, melhorou demais, nóis mudemos $90 \%$. Comecei lá de baixo, fui trabalhando, trabalhando, hoje eu não reclamo de minha vida não, tá muito é boa (ENTREVISTADO 04).

É quase toda coisa que mudou pra melhor, tem uma coisa que tá pior, muito, é a irresponsabilidade do povo, a roubalheira dos objetos da gente, some gado, some os animal, e toda coisa que eles acham é roubando os outro, agredindo os outro. Agora mesmo um rapaz que trabalhou pra mim, pegou o dinheiro e foi pra o Montes Altos e um cabra tomou o dinheiro dele na estrada, tem essas coisas que tá muito pior de antes. Antes, quando nóis viemo pra cá, noite de muito calor, nóis dexava a janela aberta, apesar de que tem a estrada que passa bem pertinho aqui, hoje em dia não tem mais coragem de fazer isso. Graças a Deus a gente já tem energia, já tem como esfriar mais um pouco, porque não pode abrir janela. Hoje não se pode confiar em quase ninguém (ENTREVISTADO 03).

A evolução do tempo é mais de 1000 vezes. Minha esposa criou os filhos carregando nas costas, buscando água na fonte e pisando o arroz, buscando a lenha no mato. Fazendo tudo, tudo, tudo.

Eu ia era para o campo ou para a cidade vender gado e negociar e a esposa tinha que dar conta. A lenha acabava e ela tinha que ir para o mato cortar a lenha de machado.

Hoje não! Hoje nós temo o fogão de lenha, porque gostam mesmo. Mas tá aí o fogão de seis bocas novinho, a água pela torneira, energia e assim por diante. Acabou até a estrada da fonte. A energia chegou mais ou menos em 2009. Mas, antes disso, já tinha energia a diesel, o motor. Hoje minha esposa vai tomar banho, lava logo a roupinha dela no banheiro. Antes era trouxa na cabeça, a bacia e o filho de um lado. Era assim (ENTREVISTADO 01).

De acordo com as falas dos entrevistados, o modelo de vida do sertanejo tem sido modificado pelas novas técnicas que chegaram à localidade e que elegeram uma outra funcionalidade na região. Exemplos como o da instalação da energia elétrica, antenas de telefones celulares e internet, melhoria na pavimentação das estradas, circulação de automóveis, entre outros componentes, têm se colocado como importantes objetos favorecedores da interligação desse lugar (Sul do Maranhão), com relações globais. Seria um acontecer solidário, conforme nos aponta Santos (2001), no qual "a divisão internacional do trabalho pode ser considerada a energia desse movimento" (SANTOS, 2001, p, 157).

Ainda sobre a interligação espacial, que contribui para a existência de uma unicidade planetária e histórica, não dissociada da diversidade, própria dos lugares, elencamos a explicação de Santos (2001, p. 158):

Muda o mundo e, ao mesmo tempo, mudam os lugares. Os eventos operam essa ligação entre os lugares e uma história em movimento. O lugar, aliás, define-se como funcionalização do mundo e é por ele (lugar) que o mundo é percebido empiricamente. 
Um subespaço é uma área contínua do acontecer homólogo ou complementar, do acontecer paralelo ou hierárquico. Em todos esses casos, trata-se de um acontecer solidário, que define um subespaço, região ou lugar.

É estar em permanente movimento, qualificado por meio do ingresso de lógicas de fora que se entrecruzam com lógicas já existentes, podendo assim inseri-las como artefatos, práticas e modo de vida pertinentes ao sociocultural. Grosso modo, ocorre uma transição territorial, passiva à troca, à exploração, como também à subjetividade. Nesse processo, há a incessante relação entre o lugar e o mundo, que faz com que concebamos o mundo a partir do nosso lugar, portanto, não podemos pensá-lo desligado de uma diferenciação quanto aos demais (SANTOS, 2002), mesmo que contenham elementos de uma lógica racional homogeneizadora.

Esse debate nos leva a pensar o lugar por meio das mais diversas articulações, em um amplo cenário de (des)encontros, (des)conexões, exclusões, através da integração entre tempo e espaço. Está entendido "como um tecer de estórias em processo, como um momento dentro das geometrias de poder, como uma constelação particular, dentro de topografias mais amplas de espaço e, como em processo, uma tarefa inacabada" (MASSEY, 2009, p. 191). Assim, a constituição das ações se consolida por meio das negociações entre lugares.

Reportando-nos para o Sertão sul-maranhense, onde estão inseridas questões da alteridade entre os diversos sujeitos que situam a região, como elementos diferenciados na forma de proceder suas atuações, as intencionalidades de cada grupo, com seus valores, acarretam uma justaposição, uma alternância entre o velho e novo, que, de algum modo, provocam conflitos, nos quais se incluem disputas territoriais, insegurança física e emocional e, principalmente, a maneira de enxergar o outro enquanto sujeito. Esse fato, analisaremos adiante.

\section{O CONVÍVIO COM O "OUTRO"}

Dos aspectos que sublinham a vida sertaneja, os conflitos ocupam, sem dúvida, um importante papel. Primeiramente, na época da ocupação pelos vaqueiros deram-se os embates sangrentos com os indígenas, motivadas por disputas territoriais, e as contendas entre famílias, que tinham conotação de poderio, principalmente político, como bem assinalou Carvalho (2000), Cabral (1996) e Paula Ribeiro (2002).

Tais conflitos nos revelam mais do que disputas territorial, política e econômica. Isso porque aí não está ancorado apenas o material, mas o imaterial, o simbólico, o subjetivo e a identidade, que se constrói de forma relacional, pois, para que ela exista, há a dependência do diferente, de uma identidade que esses sujeitos - no caso os sertanejos - não possuem, mas que fornece as condições para que ela exista, fazendo com que a identidade seja marcada pela diferença (HALL; WOODWARD, 2008).

$\mathrm{Na}$ busca pelo entendimento do espaço sertanejo em sua totalidade, no qual inclui compreender os sujeitos, vimos que aparentemente o que mais os angustia, em alguns casos, continua a ser a disputa por território. No caso da fazenda Alegria, município de Montes Altos, esta propriedade se encontra dentro de uma área demarcada para a reserva indígena dos Krikati. Alguns proprietários não receberam a indenização de suas terras, na maior parte dos casos por não acordo entre proprietários e a Fundação Nacional do Índio - FUNAl, a qual ofereceu valores irrisórios pelas benfeitorias, surtindo resistência pelo lado dos sertanejos para a não entrega da propriedade. Nesse caso, o conflito não envolve só o território, envolve o medo de perder o que está construído e que pertenceu aos seus antepassados, que, no caso, não pertencerá mais às futuras gerações, comprometendo, assim, o prosseguimento existencial da família naquele lugar. Consequentemente, ameaça a memória e a identidade do grupo.

Segundo conversas tidas com sertanejos, os rumores a respeito da demarcação da área indígena Krikati remontam a mais de cinquenta anos, quando começaram a aparecer pelo Sertão pessoas investigando, fazendo estudos em torno do que teria sido local de morada dos indígenas. A localização da referida terra indígena abrange os municípios de Amarante do Maranhão, Lajeado Novo, Montes Altos, Ribamar Fiquene e Sítio Novo. É banhada por rios e córregos das bacias do Tocantins, como Lajeado, Arraia, Tapuio, Campo Alegre, e Pindaré/Mearim. 
De acordo com a FUNAI, as primeiras notícias históricas que fazem referência específica aos Krikati buscam informar que, em 1814, este povo foi atacado por uma Bandeira, a de São Pedro de Alcântara, quando se verificaram muitas mortes e houve uma dispersão muito grande. Isso coincide com a conquista das terras Timbira, pelos brancos, que se efetivou em sua maior extensão no primeiro quartel do século XIX, dentro de um grande vácuo jurídico, ou seja, entre a extinção do Diretório dos Índios pombalino na última década do século precedente e a primeira disposição legal referente a índios do Brasil independente, que somente ocorreu no Ato Adicional que emendou a Constituição do Império em 1834. De lá para cá, após os grandes ataques armados deflagrados naquela primeira parte do século, os Krikati e os demais Timbiras conheceram um longo período de dispersão e de definhamento de toda ordem.

Como resultado, os sobreviventes projetaram conflitos ao entrar em contato com as fazendas que fazem criação extensiva de gado. Esses fatores aconteceram de forma hostil, pois, de um lado, estão os fazendeiros e/ou pequenos lavradores, sertanejos, que reclamam ser a terra necessária para suas sobrevivências econômicas e existenciais, do outro lado, os indígenas, que têm a terra também enquanto meio existencial. Por outro lado, há o Estado, que não intervém de modo adequado, pois, ao estabelecer o cumprimento da retirada da posse da terra dos sertanejos para repassá-la aos índios, não cumpre com seriedade o pagamento das indenizações. Para alguns, a quantia foi dispensada, mas, para grande parte, não. O que acarretou na inviabilização da desocupação da área por todos os proprietários.

A respeito dos conflitos vividos entre índio e fazendeiro e sobre a demarcação da terra indígena, eis os relatos abaixo do Entrevistado 03.

Conflito aqui que se fala muito é que demarcaram a terra pra os índios, mas não obrigaram o povo todo sair não. O que vimo aqui e não saimo, nem todo mundo sabe. Eu não digo que não saio, mas é preciso ser mermo puxada de dentro de casa, mas se não for, nóis não sai não. Eles não produzem nada. E se Deus é por nóis, quem será contra nóis. Apesar da idade, nóis não amolecemo não, eles andaram por aí pelo serviço (Polícia Federal e FUNAI), chegaram já o sol pendido e viram as coisas, mas não ficaram sabendo nem o que era nosso, porque não mandemo ninguém mostrar. Eu digo que essa força não foi tirada da gente, Deus é que deu essa força.

Saiu quem quis, a gente não quis, eles nunca botaram faca em ninguém para saírem de suas casas. O povo da polícia Federal e da FUNAl estiveram aqui e nóis resistimo aquele dia todin aqui e eles querendo que a gente fosse mostrar as coisas, fazer um levantamento, nóis nunca aceitamos e até hoje tamu aqui, graças a Deus. Se for um caso de um pagamento que dê pra gente comprar uma outra coisa pra gente, aí tudo bem. Do jeito que eles oferecem não adianta vim pra cá com carinha de bons amigo não que eu não aceito, de jeito nenhum, porque não é possível a gente sair do que foi adquirido pelos nossos pais. Aqui não foi, mas eu já comprei com a produção que trouxe da família, então eu posso dizer que foi adquirido de herança de nossos pais, aí eu pegar e entregar tudo, eles nos deixaram alicerçado, aí entregar tudo pros outros. Eu disse pra eles, aqui nada é nosso, tudo é de Deus, então deixou pra nóis se manter e criar nossa família até o fim da vida. Tomar eu não privo, agora eu entregar, não entrego não.

Quanto aos conflitos entre famílias, o Entrevistado 02 diz:

Primeiro é porque as pessoas tinham muita ganança com as terras, querendo só os lugar melhor. Depois foi tirado essas terras indígenas, eu mesmo fui tirado os locais que tinha, que fui preciso começar outro local. Mas graças a Deus num tô achando muito ruim não, eu tô bem localizado, num posso nem reclamar.

De acordo com os relatos, podemos observar que, no conflito existente, está inserido também o "ser diferente". Um fator que nos chama a atenção é a crença segundo a qual o indígena não produz nada, dessa forma, para o indígena, conforme o sertanejo, a terra não tem serventia nenhuma, pois a função da terra para o sertanejo é que ela sirva para produzir.

São simbologias diferentes que respingam na constituição identitária e na forma de enxergar a si mesmo e ao outro. De forma similar é a distinção existente entre o sertanejo sul-maranhense e o sulista produtor da soja que chegou ao Maranhão em fins da década de 1970. Para o sulista, o sertanejo se configura como um sujeito arcaico, preguiçoso, porquanto não sabe lidar com técnicas modernas para o cultivo da terra. Para o sertanejo, o sulista é o outro que chega de longe, que não 
gosta do lugar, chegou para destruir a natureza, explorar, expropriar e que, somente ele, o sulista, por produzir muito, consegue grandes financiamentos bancários, embora viva endividado, situação que o sertanejo abomina.

As terras aqui era tudo de família, passando de pai para filho. Mas os novos não querem conservar e venderam e tão desabando, derrubando tudo e eu em cima dizendo: olha a cabeceira da água. Aqui nunca teve um desmate desse. Desmatando pra plantar soja, arrancam até a raiz, aí cadê a raiz, cadê a frieza para conservar a água? (ENTREVISTADO 03).

[...] tem as máquinas aí que faz tudo, mas só para as grandes empresas, os grandes milionários, só pra quem pode [...].

Os vizinhos têm grandes lavouras para todo lado, mas nós pobre tivemos essa melhorazinha depois do Lula, com Bolsa Família (ENTREVISTADO 01).

Desse modo, à medida que o tempo foi decorrendo e que novas nuances foram surgindo, novas e mais relações tensas e conflitantes foram emergindo, mesmo porque entre o indígena e o sertanejo o problema existente desde o século XVIII não desapareceu, para ambos há o "outro" e, para tanto, a não aceitação. Só que, na atualidade, existem vários estranhamentos, em decorrência do processo de reocupação ocorrido nos fins de 1970 em diante, que acarreta, com a chegada na localidade de processos globalizantes, outras formas de estruturação socioespacial. Nesse sentido, uma nova fronteira é posta em construção, colocando em evidência o diferente, ao mesmo tempo em que submerge a necessidade dos sujeitos que ali já estavam de se reinventarem, para que possam ficar o mais próximo possível desse novo e "moderno", ocasionando um impacto profundo na forma de existir, que abarca diversas dimensões e significações. Candau (2011, p. 27) caracteriza da seguinte forma:

Esses destaques das "dimensões" e das "significações" da identidade são geradores de diferenças ou, mais exatamente, de "fronteiras sociais" escorregadias a partir das quais os atores estimam que as coisas e pessoas - "nós" versus "os outros" - são diferentes. Essas variações situacionais da identidade impedem de reificá-la, de reduzi-la a uma essência ou substância.

Retornamos, então, ao que já foi mencionado pelos nossos interlocutores sobre as outras dimensões que os conflitos abarcam na vida do sertanejo hoje, sendo destaque o sentimento de insegurança quanto a sua proteção. Assim, relembramos o que o Entrevistado 03 nos confidenciou em seu relato sobre a vulnerabilidade sentida por conta dos roubos ocorridos na localidade, acarretando até mudanças de hábitos.

A confiança, que funcionava em tempos passados como garantia de moeda de troca, tem se tornado rara. Se há mais ou menos trinta anos as negociações e os comprometimentos eram ajustados tendo como garantia a "palavra dada", no presente tem sido difícil confiar nas pessoas. Tal situação é colocada pelos mais velhos como uma característica decorrente de irresponsabilidade, desrespeito, rejeição ao trabalho e ambição ao alheio pelas novas gerações. Além disso, existem outros problemas, sobretudo os que dizem respeito às mudanças climáticas e pluviométricas que estão ancoradas na incidência dos desmatamentos da vegetação original para plantio de pastagens e da monocultura, principalmente a soja e o eucalipto, transformando os córregos em montantes de areia, prejudicando a sociobiodiversidade.

Tendo em vista o que ouvimos acerca dos conflitos que permeiam a vida do sertanejo, construímos um quadro explicativo sobre o que caracteriza tais conflitos. 
Quadro 02 - Quadro conceitual dos conflitos referentes à vida no Sertão

\begin{tabular}{|c|c|}
\hline Conflitos com indígenas & $\begin{array}{l}\text { Os conflitos com os indígenas existem desde a época da ocupação, } \\
\text { pois, quando o vaqueiro chega a esse território, já havia grandes } \\
\text { grupos indígenas, que foram confrontados e a grande maioria, } \\
\text { assassinada. Nos últimos anos, foram criadas reservas indígenas, o } \\
\text { que culminou em conflitos, embora não tenha tido confronto. Tais } \\
\text { conflitos são também na ordem dos valores e das subjetividades. }\end{array}$ \\
\hline Conflitos com sulistas & $\begin{array}{l}\text { Nas décadas de } 1970 / 1980 \text {, chegam ao Sul do Maranhão os } \\
\text { denominados "sulistas", atraídos pelo "baixo preço" da terra e por } \\
\text { financiamentos bancários para a produção. Tal processo foi } \\
\text { intensificado com a modernização territorial da região, que trouxe, por } \\
\text { sua vez, expropriação, exploração e aumento da pobreza, com } \\
\text { consequências para os espaços urbanos, por exemplo, o crescimento } \\
\text { do espaço periférico e da violência urbana. }\end{array}$ \\
\hline Insegurança física & $\begin{array}{l}\text { Há um medo no tocante à integridade física, por isso as residências } \\
\text { tendem a ser mais protegidas e vigiadas. }\end{array}$ \\
\hline $\begin{array}{l}\text { Insegurança quanto aos } \\
\text { bens materiais }\end{array}$ & $\begin{array}{l}\text { Existência da necessidade de vigiar os bens materiais, como o gado, a } \\
\text { casa, demais animais e as roças, por causa do aumento do número de } \\
\text { roubos e furtos. }\end{array}$ \\
\hline Insegurança emocional & $\begin{array}{l}\text { Devido às mudanças dos costumes, o medo de serem roubados e a } \\
\text { necessidade de fazerem parte do "moderno", o sertanejo carrega } \\
\text { insegurança quanto ao amanhã e no tocante ao emocional. }\end{array}$ \\
\hline $\begin{array}{l}\text { Existência de usuários de } \\
\text { drogas e } \begin{array}{l}\text { bebidas } \\
\text { alcoólicas }\end{array}\end{array}$ & $\begin{array}{l}\text { As drogas e as bebidas alcoólicas fazem-se presentes de forma mais } \\
\text { acentuada do que em períodos anteriores. }\end{array}$ \\
\hline Ausência de mão de obra & $\begin{array}{l}\text { Há relatos de que é muito dificultoso encontrar trabalhadores para as } \\
\text { roças, para o labor com o gado. A justificativa encontrada é que } \\
\text { poucos ainda querem viver na roça. }\end{array}$ \\
\hline Violência & $\begin{array}{l}\text { Com o aumento de usuários de drogas ilícitas, bebidas alcoólicas e do } \\
\text { desemprego, a violência tem se reafirmado um componente do Sertão. }\end{array}$ \\
\hline Escassez de chuvas & $\begin{array}{l}\text { As chuvas não vêm com a mesma abundância de trinta anos atrás, } \\
\text { quando rios, riachos e lagoas transbordavam e chegavam a } \\
\text { inviabilizar, inclusive, os deslocamentos. As secas prejudicam as } \\
\text { lavouras, a criação de animais e a vida como um todo. }\end{array}$ \\
\hline
\end{tabular}

Fonte: ROCHA, R. G. Pesquisa de campo, 2017.

Em suma, se por um lado, vimos que as práticas e o modo de vida sertanejo contribuem para que haja determinadas especificidades socioespaciais no Sul do Maranhão, por outro, a mistura de sujeitos e a alocação de objetos nas últimas décadas têm garantido a esse território uma multiplicidade de acontecimentos sociais, econômicos, políticos e culturais, que colocam em xeque o Ser sertanejo.

\section{CONSIDERAÇÕES FINAIS}

A construção de um lugar pelos sertanejos, no Sul do Maranhão, guarda especificidades com a forma de ocupação dessa região, relacionada à chegada de criadores de gado, que foram atraídos pelos fatores benéficos da natureza, como: relevo aplainado, verdejantes pastos, clima agradável, presença de perenes e caudalosos rios e pelo "vazio" demográfico. No concernente às relações históricas guardadas entre o sertanejo de hoje, vinculado aos costumes citadinos, e ao sertanejo de ontem, fechados em si por conta das dificuldades de vinculo social, econômico e político, com outras regiões e, por isso, dotados de modos de vidas arcaicos, há diferenciações no que tange ao modo de ver o mundo, nos desejos, nas relações sociais e, portanto, nos componentes culturais, que estão ligados ao modo de vida global, destarte, há o desejo do novo, da inserção no/do moderno.

Não obstante, notamos em conversas informais com sertanejos idosos e que residem, desde seus nascimentos, na localidade, que os espaços da infância, da mocidade e dos caminhos trilhados permanecem guardados na memória, como a casa onde nasceu e viveu a infância, as festividades religiosas, o trabalho na roça e nos afazeres domésticos, bem como as relações de sociabilidade com 
os irmãos, pais, tios, primos, amigos, padrinhos e com os demais do grupo. Nesse sentido, existe toda uma trajetória de reestruturação espacial e da vida que é reconstruída pela memória desses sujeitos, o que nos permite compreender o que foi e o que é o sertão e o ser sertanejo.

Deve-se mencionar que a espacialidade construída por esses sujeitos encontra-se prenhe de suas subjetividades e de relações identitárias, o que nos permite enxergar a objetividade impressa no espaço geográfico. Os sertanejos sul-maranhenses têm construído um lugar, principalmente no espaço rural ou em pequenos aglomerados urbanos em que as práticas são muito mais rurais que urbanas, oriundas de lógicas sociais pré-existentes. Destaca-se, ainda, o caráter de fronteira existente na região, que se caracteriza muito mais por ser social do que econômica, pela existência de conflitos inerentes a sua própria existência nesse tempo de fluidez intensa e pela presença do Outro.

Ao refletir sobre esses pontos, nossa inquietação partiu da busca de compreender o mundo que qualifica o Sertão e os sertanejos no/do Sul do Maranhão, corroborando para que sejam apontados caminhos e outras reflexões, como sugerem as seguintes questões: quais realidades materiais e imateriais existem ainda no Sertão para que possamos concebê-lo como um ente dotado de singularidades? A partir de quais elementos culturais e identitários podemos entender os sertanejos enquanto sujeitos? Como os sertanejos sul-maranhenses lidam com o Outro (como, por exemplo, a agroindústria)?

\section{REFERÊNCIAS}

ALMEIDA, M. G. A Propósito do trato do invisível, do intangível e do discurso na Geografia Cultural. Revista da Anpege, v. 9, n. 11, p. 41-50, jan./jun. 2013. https://doi.org/10.5418/RA2013.0911.0004

ALMEIDA, M. G. de. Geografia Cultural: contemporaneidade e um flashback na sua ascensão no Brasil. In: MENDONÇA, F. A. et. al. (Org.). Espaço e Tempo: complexidade e desafios do pensar e do fazer geográfico. Curitiba: Associação de Defesa do Meio Ambiente e Desenvolvimento de Antoina (ADEMADAN), 2009. p. 243-260.

ANDRADE, M. C. de. A terra e o homem no Nordeste: contribuição ao estudo da questão agrária no Nordeste. 6. ed. Recife: Editora Universitária da UFPE, 1998.

ASKENAZI, L. H. El Analisis cultural del espacio: contribuicion a uma geografia crítica. In: CELIS, A. M. (Coord.). Reflexiones sobre el espacio em las ciências sociales: enfoques, problemas y líneas de investigación. Cuajimalpa, México. 2010. p. 283-306.

BRANDÃO, C. R. No rancho fundo: espaços e tempos no mundo rural. Uberlândia: EDUFU, 2009. https://doi.org/10.14393/EDUFU-978-85-7078-169-7

CANDAU, Joel. Memória e Identidade. São Paulo: Contexto, 2011.

CARVALHO, C. O Sertão: subsídios para a história e a geografia do Brasil. 2. ed. Imperatriz: Ética, 2000.

CABRAL, M. do S. C. Caminhos do gado: conquista e ocupação do Sul do Maranhão. São Luís: SIOGE, 1992.

CASTELLS, M. O poder da identidade. Tradução: Klauss Brandini Gerhardt. São Paulo: Paz e Terra, 1999. p. 21-92.

CHAVEIRO, E. F. Corporeidade e lugar: elos da produção da existência. In: MARANDOLA JR., E. et. al. (Org.). Qual é o espaço do lugar? Geografia, epistemologia, fenomenologia. São Paulo: Perspectiva, 2012.

COELHO NETO, ELOY. História do Sul do Maranhão: terra, vida, homens e acontecimentos. Belo Horizonte: Editora São Vicente, 1979.

CRUZ, V. C. Itinerários teóricos sobre a relação entre território e identidade. In: BEZERRA, A. C. A. et. al. (Org.). Itinerários Geográficos. Niterói: EdUFF, 2007. p. 13-35.

GENIS, A. D. La construcción de la identidad en America Latina: una aproximacíon hermenêutica. Montevideo: Nordan-Comunidad, 2004. p. 19-41. 
HALL, S. Identidades culturais na pós-modernidade. Tradução: Tomaz Tadeu da Silva; Guacira Lopes Louro. Rio de Janeiro: DP\&A, 1997.

HALL, S.; WOODWARD, K. Identidade e diferença: a perspectiva dos Estudos Culturais. In: SILVA, T. T. da. (Org.). 8. ed. Petrópolis, RJ: Vozes, 2008.

LAP, Tu N. Identité culturele: la relativité de la diversité. In: BARRAK, A. et. al. (Org.). Diversité Culturelle et mondialisation. Paris: Autrement, 2004. p. 80-95.

MELLO, J. B. F. de. O triunfo do lugar sobre o espaço. In: MARANDOLA JR., E.; HOLZER, W.; OLIVEIRA, L. (Org.). Qual o espaço do lugar?. São Paulo: Perspectiva, 2014. p. 33-68.

OLIVEIRA, L. de. O sentido do Lugar. In: MARANDOLA JR., E. et al. (Org.). Qual o Espaço do Lugar? Geografia, Epistemologia, Fenomenologia. São Paulo: Perspectiva, 2012. p. 03-16.

PAULA RIBEIRO, F. de. Memórias dos sertões maranhenses. Reunidas aos cuidados de Manoel de Jesus Barros Martins. São Paulo: Editora Siciliano, 2002.

PENNA, M. O que faz ser nordestino: identidades sociais, interesses e o "escândalo" Erudina. São Paulo: Cortez, 1992. p. 49-81.

RELPH, E. Reflexões sobre a emergência, aspectos e essência de lugar. In: MARANDOLA JR., E.; WERTHER, H.; OLIVEIRA, L. (Org.). Qual o espaço do lugar?: geografia, epistemologia, fenomenologia. São Paulo: Perspectiva, 2014. p. 17-32.

SANTOS, M. Da Totalidade ao Lugar. São Paulo: Editora da Universidade de São Paulo, 2001.

SANTOS, M. A Natureza do Espaço: Técnica e Tempo. Razão e Emoção. São Paulo: Editora da Universidade de São Paulo, 2002.

TUAN, Yi-Fu. Espaço e Lugar: a perspectiva da experiência. São Paulo: Difel, 1995.

VICENTINI, Albertina. Regionalismo literário e sentidos do sertão. Sociedade e Cultura, v. 10, n. 2, p. 187-196, jul./dez. 2007. https://doi.org/10.5216/sec.v10i2.3140

Recebido em: 20/09/2020

Aceito para publicação em: 19/11/2020 